\title{
Using a Central Vehicle Holding Compound (VHC) in an Open Pipeline Automotive Order Fulfilment System: A Simulation Study
}

\author{
Bart L. MacCarthy ${ }^{1}$, Tamer Ovutmen ${ }^{2}$ \\ ${ }^{1}$ Nottingham University Business School \\ Jubilee campus, Nottingham, NG8 1BB, UK \\ Bart.MacCarthy@nottingham.ac.uk \\ ${ }^{2}$ Bain \& Company, Inc. \\ 40 Strand, London WC2N 5RW, UK \\ Tamer.Ovutmen@bain.com
}

\begin{abstract}
Satisfying requests for specific vehicle variants in a timely manner may increase profit margins for the automotive producer and automotive dealers and may reduce the need to incentivise customers financially to make a purchase. Open pipeline order fulfilment systems have emerged in the automotive sector to allow dealers to fulfil a customer in a number of ways. Not only can a dealer search its own stock for a suitable match to a customer's requested vehicle specification, the dealer can also search for a suitable vehicle in the planning, assembly or distribution pipeline. If a suitable match cannot be found, the dealer can submit a specific Build-to-Order request to the producer. This study examines the impact of adding a central vehicle holding compound (VHC) in such a system. Any dealer can search for a suitable vehicle match in the VHC. A simulation study of a real automotive fulfilment system is conducted to examine the effects on order fulfilment performance of establishing a VHC in a specific market. The simulation model incorporates important features that affect the management and control of the fulfilment system. The study shows that establishing a VHC in an open pipeline system has a significant effect on the level of use of each fulfilment mechanism and on fulfilment performance. A VHC results in significant reductions in lead time but can increase the total stock level in the system if the VHC operating conditions are not determined carefully. The insights and implications of the findings are discussed in detail. They are valuable in providing a base line to consider investment in a VHC and to decide the most appropriate operating policies.
\end{abstract}

Keywords: Order fulfilment; automotive, open pipeline; vehicle holding compound (VHC). 


\section{Background}

Volume automotive producers require effective order fulfilment systems to meet demand from customers seeking to purchase vehicles. A major complicating factor is the very high number of variants offered for many vehicle models (Fredriksson \& Gadde, 2005; Brabazon et al., 2010; Stablein et al., 2011; Brabazon \& MacCarthy, 2012). The customer base is also diverse. Customers may be of different types (e.g. retail customers and fleet customers) and individual customers differ in their desire to specify a vehicle in detail and in their willingness to compromise on vehicle specification.

A regional market typically comprises of many dealers interacting with the automotive producer to satisfy demand for their customers. Open pipeline order fulfilment systems have emerged in the volume automotive sector to satisfy demand in many automotive markets (Holweg \& Pil, 2004; Tomino et al. 2009; Brabazon et al. 2010; Lim et al. 2014; Stablein et al. 2014). In such systems, vehicle assembly schedules are based on a combination of forecasts and orders from dealers for specific vehicles based on customer requests. Importantly in such systems, all vehicles produced to forecast are allocated to dealers on an agreed basis, typically based on dealer size and sales volumes. In general a dealer will not have specific customers for all of its allocated vehicles.

Open pipeline systems allow a dealer to fulfil a customer seeking a particular vehicle variant in a number of ways. These are illustrated in Figure 1a for a system with multiple dealers. A dealer receiving a customer order may be able to fulfil the customer from its own local stock if a suitable match can be found, indicated by the dashed line arrow labelled ' $a$ '. If a match is not found a dealer can search its allocated vehicles in the pipeline for a suitable match, indicated by arrows 'b', 'c', 'd' (i.e. the vehicles the dealer has been allocated that are 
scheduled for production in the plan or in assembly and those in transit to the dealer). If a suitable match cannot be found, the dealer can submit a specific Build-to-Order (BTO) request to the producer to satisfy the customer, indicated by arrow 'e'. Depending on how the system operates a dealer may also be able to satisfy a customer in two other ways (not illustrated in Figure1a). Firstly, the dealer may be able to search the vehicles of other dealers in their local stock and those in the pipeline for a suitable match, which we call dealer trading in this paper. Secondly, the dealer may be able to amend the specification of a vehicle in the planning pipeline to match customer requirements. Each vehicle in the pipeline that is sold to a final customer (from either a dealer search or from a dealer's BTO request) cannot be allocated to another customer.

Open pipeline systems of this type allow multiple modes of fulfilment. However, they have had only a limited amount of modelling and analysis in the literature. Previous work has examined their theoretical performance (Brabazon \& MacCarthy, 2006, 2010; MacCarthy et al., 2013). However, real systems are large in scale with many interacting factors affecting operating policies and system behaviour. Large scale simulation studies have been undertaken with a major automotive producer to examine the effects of different operating policies on system performance (Brabazon et al. 2010, Ovutmen 2012).

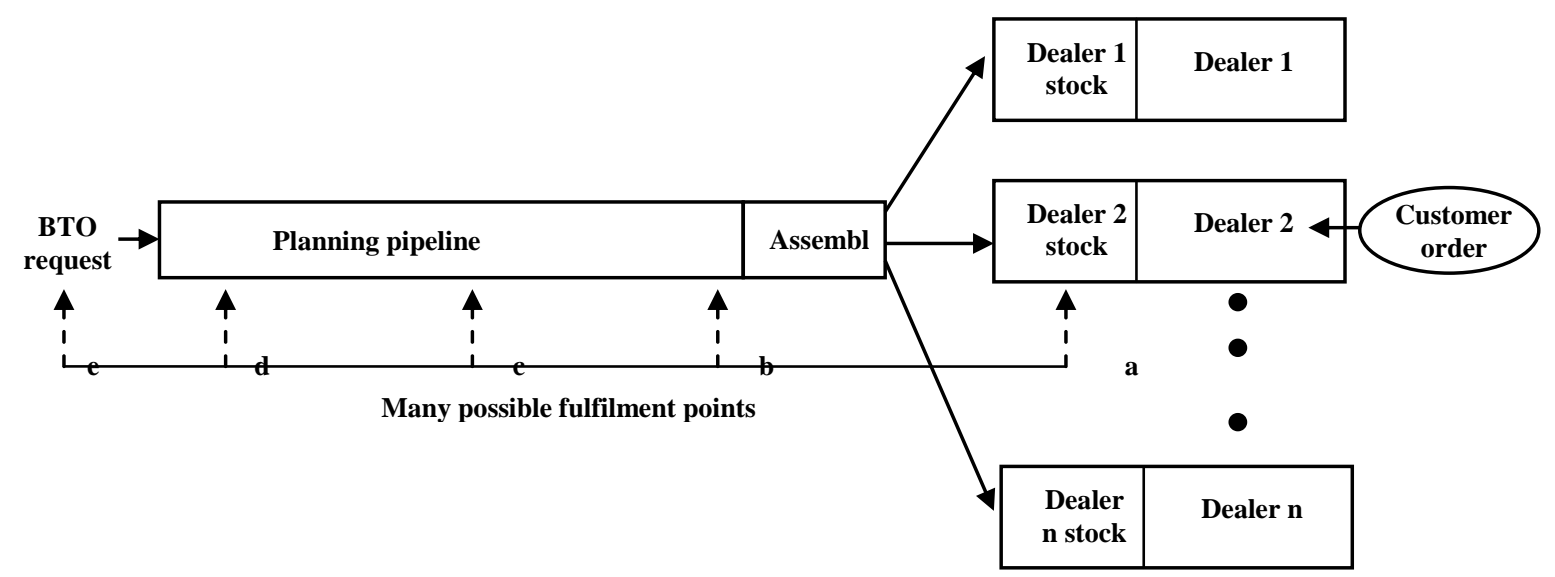

Figure 1a. An open pipeline system without a VHC 


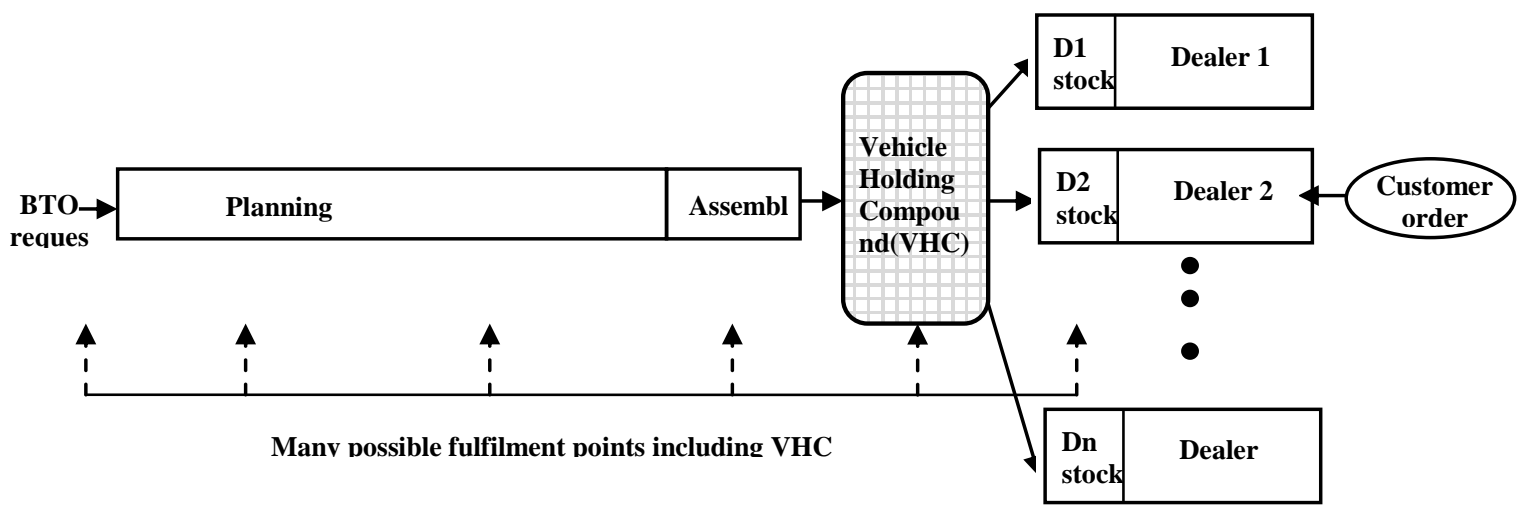

Figure 1b. An open pipeline system with a VHC

An open pipeline system may operate with or without a centralised vehicle holding compound (VHC). Previous studies have not considered a VHC in an open pipeline system. A VHC seeks to simplify and overcome the barriers of trading vehicles between dealers (cost, distance, time, dealer to dealer relationships) by holding a high proportion of unsold vehicles in a central compound and sending a smaller proportion to dealers to facilitate demonstrations and promotions. All vehicles in the VHC are allocated to specific dealers but do not have a final customer. Vehicles in the pipeline that have already been allocated to customers (from either a dealer search or a dealer's BTO request) do not go to the VHC but go to the relevant dealer to be presented to the customer. A dealer in a region is able to search for a vehicle in the VHC to find a match to the specification that a customer would like to buy. Thus, the VHC introduces a further mechanism for fulfilment in an open pipeline system as shown in Figure $1 \mathrm{~b}$. However, a VHC may operate in different ways, particularly with respect to the proportion of unsold vehicles held in the VHC and how long vehicles are allowed to remain in the VHC.

The study reported in this paper examines the impact of introducing a VHC into a real open pipeline system. It uses a large scale simulation model that replicates the processes used by a major automotive producer with a data set from a specific market. Literature relevant to the 
study is discussed in the following section. Section 3 describes the structure of the simulation model. Section 4 describes the experimental study and the performance metrics investigated. Section 5 presents the results from the experimentation. Section 6 discusses the insights and implications provided by the study for open pipeline systems in the volume automotive sector. The concluding section discusses limitations and avenues for further work. A list of terms with explanations relating to the open pipeline fulfilment systems is provided in the appendix.

\section{Literature Review}

In the volume automotive sector, there has been significant interest in improving service levels to customers by satisfying customer requests for particular vehicle specifications quickly whilst maintaining the cost efficiencies of volume production. Mass Customization and Build-to-Order strategies have been widely advocated and discussed for the sector (Alford et al. 2000; Holweg \& PIl, 2001; Holweg \& Pil, 2004; Fredriksson \& Gadde, 2005; Brabazon et al., 2010). The attraction of such strategies is clear - improved customer satisfaction, potentially higher profit margins, potentially a reduction in inventory holding of finished vehicles and a reduced need to incentivise customers to purchase vehicles. However, there have been significant operational challenges in adopting pure Build-to-Order strategies in the volume automotive sector (Agrawal, 2001; Holweg \& Pil 2001, Holweg \& Pil, 2004; Fredriksson \& Gadde, 2005; Brabazon et al., 2010). Holweg et al (2005) argue that the length of the planning processes in automotive order fulfilment systems, the reliance on forecasting and the limited feedback between supply and demand severely restrict the shift towards builtto-order (BTO) production. They illustrate this through a Systems Dynamics model with two vehicle variants. The level of product variety on offer is also a major challenge. Stablein et al. (2011), in a detailed comparative analysis, note the high number of variants offered by different producers, but also note how this varies by producer, model and market and that in general much fewer variants are actually produced. 
The order fulfilment systems that have now been developed by many of the volume producers in the automotive industry show many similarities (Tomino et al. 2009; Brabazon et al. 2010; Lim et al. 2014; Stablein et al. 2015). They allow dealers to satisfy customers in a number of ways whilst still allowing the producer to maintain volume production efficiencies. Dealers have the ability to search not only their own stock but the physical pipeline of vehicles and also the planned vehicle pipeline to find a match for a customer's request (as illustrated in Figure 1a above). Although these systems have been described, they have received only a limited amount of analysis to date. We discuss relevant analysis, modelling and simulation studies below.

A basic fulfilment system has a single fulfilment point, e.g. in a make-to-stock environment the customer is fulfilled from already produced finished products whilst in a make-to-order environment production is initiated or planned on receipt of a customer order. Relatively few studies have examined hybrid fulfilment systems with more than one fulfilment point. Swaminathan \& Tayur (1998) describe an approach in which customer orders are satisfied by assembling products either from basic components or from semi-finished intermediate products. Denton et al. (2003) analyse a steel industry example where a customer can be fulfilled from stock, from semi-finished products made to forecast or by initiating a make-toorder product. Meredith \& Akinc (2007) describe and analyse a manufacturing context with long production lead times where production is initiated to forecast and products in production are modified to meet incoming orders for specific variants. In general it is clear that there may be benefits in terms of order fulfilment performance from adopting multiple modes of fulfilment, although research studies have tended to consider only a small number of product variants. The related concept of Available-to-Promise (ATP) has been a wellestablished approach in some MRP-driven planning systems where products scheduled for 
production in the Master Production Schedule are allocated to customers dynamically to improve reliability in promising delivery dates (Piebernik, 2005; Stadtler and Kilger 2010). These ideas have been developed further for planning product allocations across a network of dispersed production units, sometimes called Global-Available-to-Promise (GATP). MacCarthy (2013) discusses the links between these concepts. However the contemporary pipeline management systems in the volume automotive sector are not managed using traditional MRP principles.

The modelling and analysis of order fulfilment systems where a customer may be fulfilled from any point in the system have received much less attention. Brabazon \& MacCarthy (2006) compared the theoretical behaviour of a basic open pipeline system with a conventional fulfilment system that did not allow pipeline fulfilment. They highlighted the importance of the ratio of product variety and pipeline length in determining the behaviour of each system. Brabazon \& MacCarthy (2010) examined the feasibility of modelling such a system as a Markov process but could generate results only for very small systems. MacCarthy et al. (2013) further developed the Markov-based analytical approaches with approximation schemes to derive results on order fulfilment performance for larger scale systems, identifying relationships between the level of variety, the pipeline length and the amount of initial stock in the system. These theoretical studies did not consider dealers or a VHC in the system.

Although theoretical results provide insights on the effect of system parameters, they do not take into account many of the complexities evident in real large scale automotive systems. Real systems include many dealers interacting with the producer and may include a centralised VHC. The operating policies determined by the producer for the system affect the ability of dealers to search the pipeline. Operating policies therefore affect the flexibility that 
dealers have to satisfy customer demands. Flexibility in operations management is a wide and diverse topic with an extensive and varied literature (e.g. De Toni and Tonchia 1998, Koste and Malhotra 1999, Seebacher and Winkler, 2013). In a study in Volvo cars, Fredriksson and Gadde (2005) discuss the complex interplay between process flexibility and rigidity in offering high levels of customization and variety and the need for a balance to be struck to achieve reasonable costs and lead-times. We restrict our discussion here to two specific operating policies that offer the dealer flexibility in an open pipeline system - dealer trading and the amendment of vehicle specifications in the planning pipeline.

Dealer trading is a form of routing flexibility (Koste and Malhotra 1999; Brabazon et al., 2010). Potentially, all of the unsold vehicles in the system can be made available to all customers, which may be considered as a form of transshipment (Herer et al., 2002; Ozdemir et al., 2006, 2013; Patterson et al., 2011). The potential benefits of transshipment in a network have been noted, including improvements in service level and reductions in system inventory, provided that optimal strategies can be derived (Ozdemir et al., 2006). The ability to amend vehicle specifications in the planning pipeline may be viewed as a form of mix flexibility in which changes in the production plan can be absorbed without significant negative effects (Chen et al. 1992; Koste and Malhotra 1999; Brabazon et al. 2010).

The varied literature on flexibility and related topics provides general insights but does not answer the specific questions investigated in this study. As Patterson et al. (2011) noted in their extensive review on transshipment, the vast majority of studies are theoretical, have very limiting assumptions (e.g. one product type) and are difficult to scale for large dimensional problems. The results cannot therefore be applied to predict the performance of the systems that are evident in real automotive fulfilment systems with a very large number of product variants, a large number of dealers, and a number of different fulfilment mechanisms. For the 
investigation and analysis of large scale systems, simulation modelling and/or optimization modelling are typically needed. Stablein et al. (2007) describe a generic supply network simulation environment that has been used for business process design and assessment by a major automotive OEM in the context of its upstream supply network. The environment allows an appropriate level of aggregation for different kinds of decision making. Almeder et al. (2009) discuss the use of combined optimization and simulation modelling in supply networks. They present a method where an LP is embedded in and drives a discrete event simulator and demonstrate its potential for a supply network with up to four products.

Brabazon et al. (2010) used a simulation model representative of a real automotive order fulfilment system to compare the effects of dealer trading and the potential to reconfigure products in the planning pipeline. The study quantified the relative benefits that could be derived from each of these types of flexibility in an open pipeline system over a wide spectrum of product variety levels. Although significant insights were shown, the model was limited to three dealers and could not easily be scaled up. The study did not consider a VHC in the system.

The study reported in this paper is undertaken using a large scale simulation model designed to replicate the fulfilment system of a large automotive producer interacting with a full set of dealers in a real market. It investigates the impact of introducing a VHC in this market with regard to (1) changes in the mechanisms by which customers are fulfilled, as well as changes in order fulfilment performance in terms of (2) mean lead time performance, and (3) mean stock levels in the system. These variables are of substantial interest to decision makers in the automotive industry. Changes in the proportion of customers fulfilled by each fulfilment mechanism have significant implications for the operation and management of the order fulfilment system. Lead time is a primary indicator of customer service and is much referred 
to in previous studies (e.g. Holweg and Pil, 2001, 2004; Brabazon et al. 2010). Stock levels are an important indicator of costs, which are typically borne by the producer before vehicles reach the dealer. The implications of the observed changes on the way the system performs and how well it performs for different operating scenarios are discussed in the Discussion in section 6. We do not investigate costs, which would necessitate a different kind of study. Logistics costs and to some extent stock holding costs are not simple in the downstream automotive industry (e.g. which party bears which costs) and could vary substantially depending on the producer's policy, and contractual issues and negotiations with dealers. However, we emphasise that the study here helps to inform such a study by providing clear evidence on how the fulfilment mechanisms and order fulfilment operating performance are expected to change with the addition of a VHC under different operating conditions, which is discussed further in section 6.

The study uses data from a real market to undertake the study and investigates different ways of operating the VHC with respect to the proportion of vehicles sent to the VHC and the maximum amount of time a vehicle is permitted to remain there. The study has three objectives:

1. Determine the effects on order fulfilment performance of establishing a VHC in the market under the anticipated VHC operating policies.

2. Determine the effects on order fulfilment performance of the proportion of unsold vehicles sent to the VHC from the assembly plant.

3. Determine the effects on order fulfilment performance of changing the maximum period a vehicle can be kept in the VHC before being shipped to the original dealer (the 'autoshipment' duration). 


\section{The Simulation Model}

The producer (a large automotive OEM) has provided a large data set for a specific model in a specific national market in Europe based on 3 years of sales data to identify demand characteristics and fulfilment performance for use in the simulation model. The data set has been thoroughly analysed. Each data record contained detailed information on the vehicle specification, the customer type, when it was ordered, when it was sold, the nature of the customer, when it was manufactured, when it was delivered, dealer information, whether it was traded, and/or had its specification amended. This allowed detailed analysis of order fulfilment performance in the market and allowed accurate distributions to be generated for all demand types and market share for dealers in order to run and validate the simulation model (Ovutmen, 2012).

The simulation model captures a real automotive order fulfilment system at an appropriate scale and level of detail, incorporating the important features that affect its management and control and that may impact on fulfilment performance. The model is outlined in brief here to explain how it operates. Some parts of the model have greater complexity, additional functionality and user-defined customizability than is possible to describe here in full (Ovutmen, 2012). The model is first described without a VHC and then how a VHC is included is explained. In the discussion below a 'vehicle' may refer to either a planned vehicle in the planning pipeline or a physical vehicle that has been assembled and is in transit or in stock somewhere in the system.

The simulation model has been developed using object-oriented principles in order to allow the model to be scaled and adapted to capture different markets. The model has 8 objects. The objects and their hierarchy are illustrated in Figure 2. The top level object is the main object, consisting of producer, dealer, and customer objects. The producer object consists of manager, 
wholesale, scheduler, pipeline and search objects. The pipeline object owns the pipe segment object, which divides the pipeline into months, weeks and days.

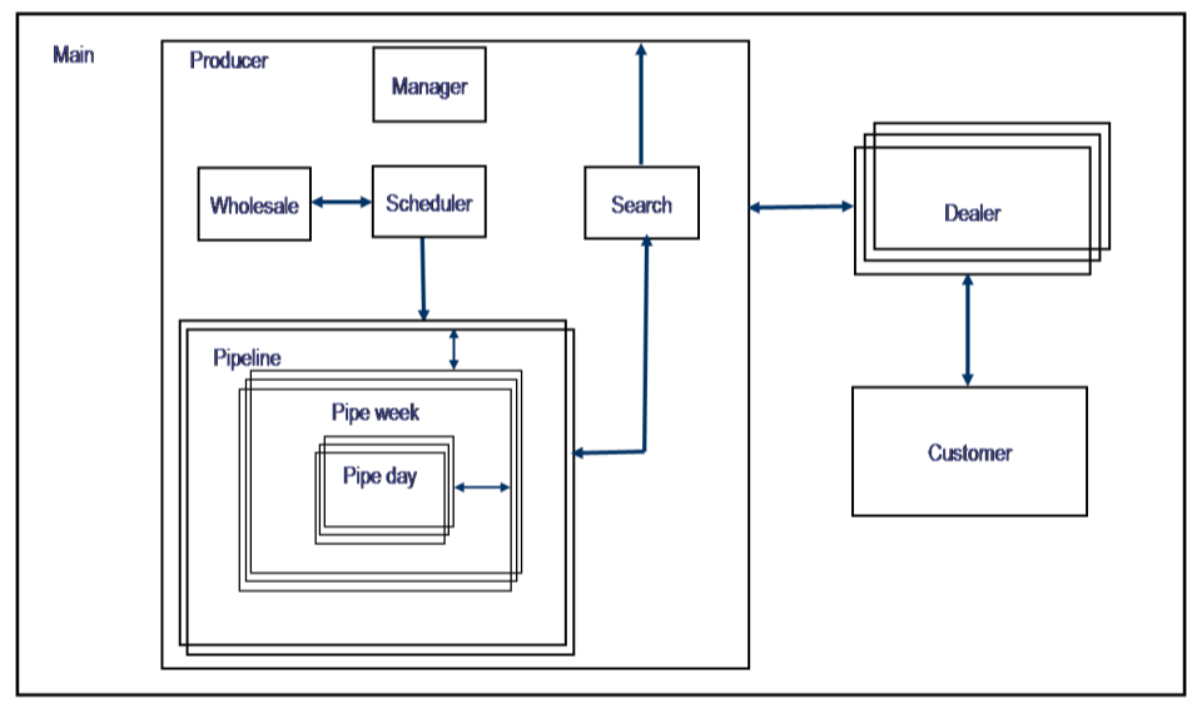

Figure 2. Object-oriented simulation model structure

In the top level hierarchy the producer, dealers and customer objects interact. Customers are created in the main level and allocated to one of the dealers in the model. The simulation sends the customer information to the dealers' object (an object is created for each dealer in the system), which fulfils the customer either from their own physical stock, from other dealers' physical stock (if trading is allowed in the system), from the pipeline of planned orders or by sending a Build-to-Order request (BTO) to the producer.

\subsection{Demand type}

The customer object is used to identify the demand type and vehicle specification for each customer created. Based on the analysis of the producer's data set, empirical demand functions have been created, which are used to randomly sample customer demand in the proportions observed in the data. A number of different classes of customer demand exist within the overall demand. The majority of demand is fulfilled via the dealer network but a 
proportion of demand is processed centrally by the producer, replicating corporate level fleet sales.

A fixed number of customers is created each day in the model, which is the same for every day in the simulation run, estimated from the volume of daily sales. The model does not take into account demand fluctuations or seasonality in demand. Customers are generated sequentially and each is processed prior to the next customer in the system being generated. The customer's willingness to compromise on the requested specification is a randomly generated probability based on an algorithm developed to govern whether or not a customer is likely to compromise on an individual vehicle feature.

\subsection{Dealers}

The data set shows that over 600 dealers sold vehicles during the period covered for the specific market considered in the study and these are captured in the model. The model uses an empirically generated distribution of dealer market share. The distribution of demand across the dealers is highly skewed with the top 10 dealers accounting for around $20 \%$ of all demand. Each dealer performs two key processes - customer fulfilment and wholesale order generation, in which they interact with the producer.

When a customer arrives at a dealer the requested vehicle specification is used to look for a matching vehicle in the dealer's own stock by comparing it with the specification of each vehicle on the unsold stock list of the dealer. The search process is governed by the Search object. If an exact specification match is found then the search finishes and the vehicle is moved from the dealer's unsold list to the sold list for delivery to the customer on the next day of the simulation. If an exact match is not found in stock then each vehicle in the dealers stock is assessed against the customer's willingness to compromise. If an unsold vehicle in the 
dealer's stock is deemed to be acceptable then it is placed on a list of potential vehicles for the customer. Failure to find an exact match in dealer stock triggers a search of the pipeline (in case an exact match or better match is available elsewhere in the system). The customer's requested specification is checked against the specification of unsold vehicles in the pipeline. The search returns a list of potential matches, which is sorted and ranked taking into account specification difference and estimated lead-time. If dealer trading is allowed (see below) then the list may contain vehicles allocated to other dealers. The ranking process seeks to achieve the best match for the customer. At the start of each day each dealer updates its stock records and checks for the arrival of sold vehicles for its customers that are awaiting delivery. Sold vehicles are delivered to the appropriate customers, removing both the customer and vehicle from the system. The search logic above is shown in Figure 3.

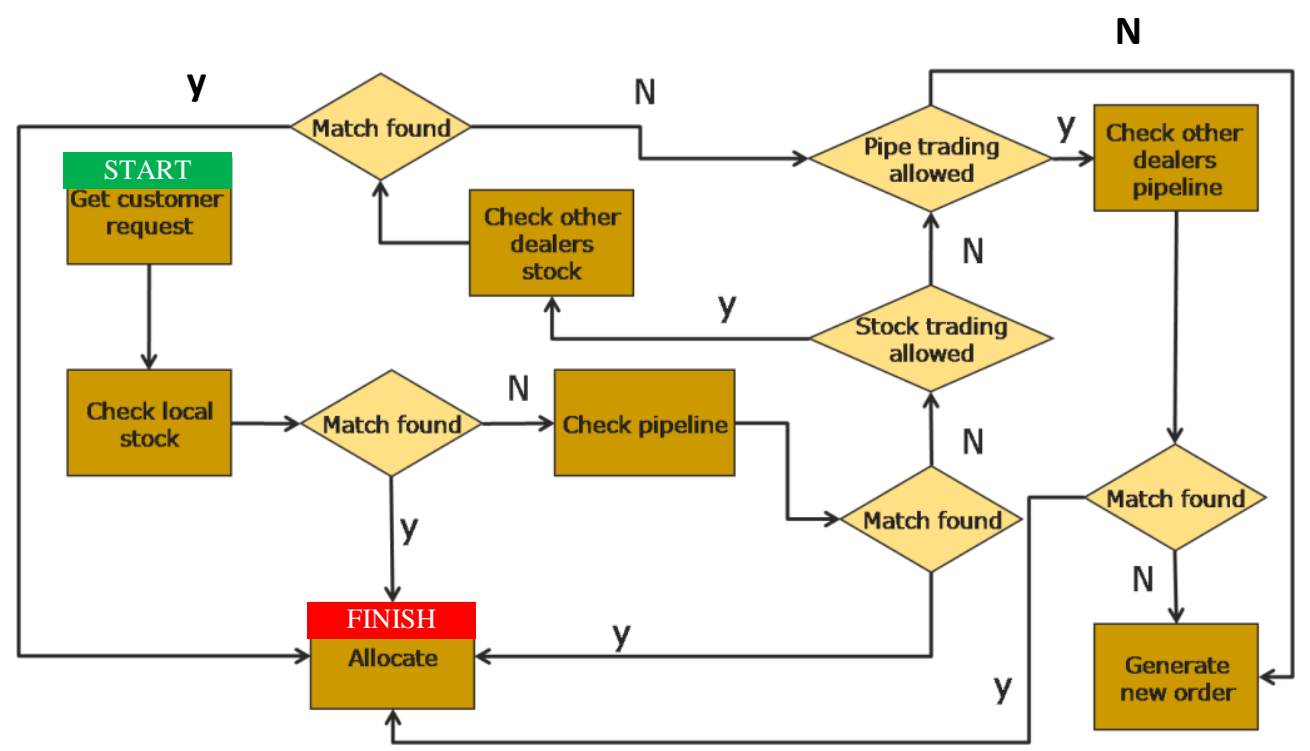

Figure 3. The search process

The wholesale order generation process is triggered at the start of each new month when each dealer generates a volume of orders to meet its volume requirement agreed with the producer. The dealer will first submit any new customer orders that it was unable to submit during the previous month and then make up any shortfall by generating stock orders whose specification is sampled from the dealer's wholesale distribution of demand. Wholesale 
demand is an empirical distribution created from the analysis of the data set. The created orders are stored as a list by each dealer, which are then passed to the producer object to collate and process with those of other dealers.

\subsection{The Producer}

The producer object owns the Manager, Wholesale, Scheduler, Pipeline and Search objects. Vehicle assembly is assumed to take place at the end of the pipeline. The producer object performs the daily process of despatching completed vehicles from the most downstream segment of the pipeline to the dealers by removing each completed vehicle from the planning and assembly pipeline and allocating a delay value to represent delivery time to the dealer. The pipeline object manages the flow of planned vehicles through the pipeline. The pipeline is arranged in segments of days, weeks and months.

The manager object calculates and allocates capacity constraints based on the volume of orders submitted for production during the next month and informs the scheduler of these capacities. The wholesale object controls the wholesale process by first receiving the initial wholesale submissions from dealers at the start of the month and then placing these orders into the unscheduled order bank which is a list of orders maintained by the producer. The wholesaling process is complex in practice and its implementation is not described fully here. Full details are provided in (Ovutmen, 2012). We note that the wholesaling process is not used as an experimental variable in this study but that the simulation model seeks to replicate how the producer interacts with the full complement of over 600 dealers.

On completion of the monthly wholesaling process the next month's orders are sequenced and scheduled into the pipeline. Each new month begins with an empty monthly segment when 
the scheduler takes the next months orders from the unscheduled order bank and places them into the monthly pipeline segment in sequence according to a defined sequencing priority.

\subsection{Product Variety}

The producer's data set provided detailed information to capture the level of product variety for the simulation in terms of the most important features defining a vehicle. The five features used in the simulation - body style, engine, transmission, series, colour - were identified by the producer as the most important for customer satisfaction. For this dataset the 'series' is a set of bundled options that determines the base of the vehicle (e.g. sports pack, comfort pack etc.). Other options were excluded from the variety level analysis as they result in a long tail in the distribution. From the data analysis, 3724 distinct combinations of body style, engine, transmission, series, and colour were observed, determining the variety level used in this study. To the best of the knowledge of the authors, no other published simulation study has used this level of variety, obtained from a real data set, with over 600 dealers for a real automotive market.

\subsection{Amendment and Trading}

The production capability of the producer may allow dealers in some markets the flexibility to amend features of a planned vehicle prior to production. The model allows this process to be introduced in a manner that reflects how a real system operates. In a real system with a two month planning pipeline there is a need to ensure a degree of stability in the assembly schedule. One week prior to a planned vehicle being assembled the order is locked and is therefore not available for amendment. Between 1 and 2 weeks prior to production only the colour can be amended. All features of the vehicle are amendable more than two weeks prior to the scheduled assembly date of the vehicle. The model can be operated with or without the amendment process. 
Two types of trading are possible in the system: pipeline trading and stock trading. Pipeline trading allows dealers the ability to satisfy a customer with a planned vehicle in the pipeline belonging to another dealer. In theory all the unsold vehicles in the planning pipeline might be made available to trade between dealers. However, the amount of trading in the system depends on dealer behaviour in the market. In the market studied dealers tend to be possessive about their orders and are often reluctant to trade their unsold products in the pipeline. The model allows a proportion of orders in the pipeline to be made available to be traded between dealers. Stock trading refers to vehicles in the stock of local dealers in the system to be made available to other dealers if they have not been sold to a customer. The dealers can search through the inventories of other dealers and propose a trade for a vehicle. In the market studied only a limited amount of stock trading was observed. The model allows a proportion of vehicles in stock to be made available to be traded between dealers.

\subsection{Including a $\mathrm{VHC}$}

All vehicles in the pipeline that have been sold (i.e., BTO vehicles and those that have been allocated to customers by dealers from a previous search process) are sent directly to the relevant dealer. A proportion of the remaining vehicles may be sent to a VHC after assembly. A VHC is added to the model by incorporating it into the producer object. A control parameter is used, which determines the proportion of unsold vehicles sent to the VHC. The logic used in despatching vehicles is changed to check whether an unsold vehicle is sent to the dealer to which it was allocated or sent to the VHC. If the vehicle is sent to the VHC it is added to the VHC stock, otherwise it is sent to the relevant local dealer and added to the inventory of that dealer. If a vehicle in the VHC is not sold for a long time period it is 'autoshipped' to the dealer that was originally allocated the vehicle. The maximum duration permitted for a vehicle in the VHC is determined by the producer and is considered in the experimental study below. 
If a VHC is included in the model, it offers another mode of fulfilment and must therefore be included in the search process. If a match is not found in the dealer's local stock, VHC fulfilment is the second mode in the fulfilment hierarchy - after local stock fulfilment and before pipeline fulfilment. For the study here it is assumed there is no need to obtain consent from the dealer who was originally allocated the vehicle to allow another dealer to have access to a vehicle in the VHC. This assumption is valid with the application of a VHC in markets where the producer has full control on allocation of unsold vehicles. The logistics times for delivery from the VHC to a dealer are assumed to be constant.

\subsection{Validation and Calibration}

The model has been through extensive testing in model development over a number of years to ensure that its fundamental conceptual logic is correct and that it captures the key decision making processes and their relationships in the order fulfilment system at an appropriate level of detail for the purposes of studying order fulfilment performance. It has been through a full cycle of critique to ensure it is conceptually accurate and logically correct for its intended purposes. Face validation with knowledgeable experts at the producer was an important part of this process (Sargent 2013). The model has been through a number of previous versions with studies reported in the literature (e.g. Brabazon et al. 2010; Brabazon \& MacCarthy 2012; MacCarthy et al. 2013). The model used in this study replicates the processes already validated in previous versions but the underlying simulation environment was re-engineered to be object-oriented. The principal reasons for this were to enable it to be scalable for different and specific market scenarios and to be easily amendable for different operational settings (e.g. including a VHC). In particular it was designed to allow multiple dealer objects to represent a full market area, which the earlier models did not have. 
The model logic and operation of the object-oriented simulation has been through the same verification and validation processes noted above to ensure that it met its intended purpose of enabling performance and behaviour of a real automotive order fulfilment system to be studied. Again, face validation by experts at the producer was an important part of this process. The object-oriented model has been used in a number of reports to the company on the likely impact of policy changes. No business process simulation model is a perfectly accurate representation of the system or entity it seeks to represent, nor should it strive to be. As Sargent (2013) has noted, the costs and benefits in model development and validation need to be weighed in attaining a model that is 'reasonable for the intended purpose of the simulation model', which in this case is to study the behaviour and performance of the order fulfilment process.

Specifying model parameters in an appropriate way and examining model outputs against known system behaviour is an important aspect of any modelling study. In developing a large scale simulation model there are significant challenges in calibration and parameterization (Banks, 2001; Ovutmen, 2012). The number of output metrics that can be tracked is large. Some output metrics are independent whilst others may be correlated to some degree. In addition, the settings specified for system parameters may affect each of the output metrics in a different way. The general approach adopted in calibrating the model was to quantify the differences between different model parametrisations and the observed data set. Key output metrics used were the observed and simulated proportions of customers fulfilled by each of the three fulfilment mechanisms and the observed and simulated mean stock level in the system. From our knowledge of the system it was clear that mean lead time was related with the fulfilment proportions (see Discussion section 6). A large number of experiments were conducted to observe and understand how these key output metrics changed for different combinations of input parameters. 
The OptQuest software built into the AnyLogic optimization software (Anylogic version 6.3.4.; www.xjtek.com/anylogic) was valuable in exploring and identifying the combined effects of changes in system parameters on system behaviour. Two parameters were identified from experimentation as being most influential on the behaviour of the system - the proportion of unsold vehicles in the pipeline available to be traded and the proportion of customers that compromise on a particular product feature. We analysed the changes in the simulation results for different ranges of pipeline trading and compromise in the system against the fulfilment proportions and the mean stock levels observed in and changes. A composite measure of mean absolute \% deviation (MAPD) was constructed as a measure of how close the simulation output was to the data set, as follows:

$d_{s}=$ stock fulfilment proportionobserved in the data

$d_{p}=$ pipeline fulfilment proportionobserved in the data

$d_{b t o}=$ bto fulfilment proportionobserved in the data

$d_{l}=$ mean stock level observed in the data

$m_{s}=$ stock fulfilment proportionfrom simulation model

$m_{p}=$ pipeline fulfilment proportionfrom simulation model

$m_{b t o}=$ bto fulfilment proportionfrom simulation model

$m_{l}=$ mean stock level from simulations model

The absolute $\%$ deviation of each of these measures is calculated as

$$
\Delta=\frac{a b s(d-m)}{d} \times 100
$$

The mean absolute $\%$ deviation is given by

$$
M A P D=\frac{\Delta_{s}+\Delta_{p}+\Delta_{b t o}+\Delta_{l}}{4}
$$

This kind of calibration approach was used in the study to enable detailed understanding of behaviour and performance of the model for different parameter sets. It was possible through 
the calibration process to identify parameter sets that could accurately replicate system performance with a MAPD error of less than 5\%. Experimental outputs from the calibrated model were also discussed in detail with key personnel at the automotive producer to confirm validity. The results showed that the simulation model was sufficiently accurate and appropriate to enable comparative studies of system performance for different modes of operation and to judge the relative effects of different operating policies. Further explanation and examples of the calibration process are given in Ovutmen (2012).

Hence we concluded that the validation and calibration processes confirmed the validity of the simulation model for the comparative experimental studies undertaken in this paper. Overall it was apparent that the model could approximate the overall system performance sufficiently closely to provide valuable insights on the behaviour and performance of the real system and allow the relative impacts of different operating policies to be evaluated.

\section{The Experimental Study}

The experimental study has been undertaken in two stages. In the first stage, the performance of several systems without a VHC is compared to a system with a VHC that uses typical VHC operating conditions. To determine typical VHC operating conditions for the study, experienced personnel in the company were consulted to identify a typical proportion of stock that would be kept in a VHC and the maximum auto-shipment duration typically stipulated by the producer. Based on the consultation and a data analysis, a VHC was established with a 70/30 (\%) split for VHC and local stock, and a 90 day auto-shipment duration. In the second stage of the study, the operating policies of the VHC are changed with respect to the split of stock held in the VHC and locally at dealers, and the maximum auto-shipment duration. 
In the first stage of the study the performance of three different non-VHC systems are compared to a system with a VHC with the typical operating conditions. The operating policies for the four systems are shown in Table 1 below. Case 1 is the first non-VHC system, which does not allow customer compromise or stock trading (NO-VHC-NCNT). Case 2 is the second non-VHC system, which does not allow customer compromise but allows a proportion of stock trading (NO-VHC-NC). Case 3 is the third non-VHC system (NO-VHC), which allows a proportion of stock trading and a level of customer compromise. These three cases are compared with a system including a VHC operating with the typical VHC conditions noted above and which also allows the same proportion of stock trading and level of customer compromise assumed in the Case 3. All other operating conditions for all four systems are the same. The ability of the dealer to satisfy a customer request from either stock or pipeline increases from Case 1 to Case 2 and from Case 2 to Case 3. The rationale for using different cases is to understand the relative impact of a VHC in markets where some of the potential fulfilment flexibilities are not readily available or are unlikely to be used by dealers.

Table 1. Cases for the First Study

\begin{tabular}{|l|c|c|c|c|}
\hline \multirow{2}{*}{} & \multicolumn{2}{|c|}{ NO VHC } & \multirow{2}{*}{ VHC } \\
\cline { 2 - 5 } & Case 1- NCNT & Case 2- NC & Case 3 & $5 \%$ \\
\hline Stock trading & No & $5 \%$ & $5 \%$ & $20 \%$ \\
\hline Stock compromise & $0 \%$ & $0 \%$ & N/A & $70 \%-30 \%$ \\
\hline $\begin{array}{l}\text { VHC/Local Stock } \\
\text { Split }\end{array}$ & N/A & N/A & N/A & 90 Days \\
\hline $\begin{array}{l}\text { Auto Shipment } \\
\text { Duration }\end{array}$ & N/A & N/A & & \\
\hline
\end{tabular}

For the second stage of the experimentation, the operating parameters of the VHC are varied. The stock split between the VHC and local dealers is studied in increments of $10 \%$ from $0 \%$ VHC to $100 \%$ VHC. The effect of changing the auto-shipment duration is studied in 15 day increments from a minimum duration of 15 days to a maximum duration of 210 days. 
The study focuses specifically on the effects of incorporating a VHC on key order fulfilment performance metrics. As discussed in section 2, the study does not consider the costs associated with implementing, managing or running the VHC, which are further discussed in section 6. The metrics investigated are:

1. The level of use of each fulfilment mechanism
a. The proportion of orders fulfilled from local stock
b. The proportion of orders fulfilled from the VHC (when operative)
c. The proportion of orders fulfilled from the pipeline
d. The proportion of orders fulfilled by BTO.

\section{Stock level}

a. Mean local dealer stock level - the mean total stock kept by all dealers locally, measured in vehicle units.

b. Mean VHC stock level - the mean stock level held in the VHC when operative, measured in vehicle units.

3. Mean customer waiting time - the mean time from receipt of a customer order to the customer receiving the vehicle, measured in days.

\subsection{Simulation Protocols}

The simulation model has been developed using Anylogic version 6.3.4. (www.xjtek. com/anylogic). A warm-up period of 1000 months was run before gathering statistics from the simulation. This extensive warm up period ensured the system reached steady state before data collection. The main reason a very long warm-up period was required was the complexity and scale of the simulated system (e.g. there are 661 dealers in the system). A month in the simulation is 28 days, so the warm-up takes a total of 28000 days. At the end of the warm-up period the simulation runs for a further 19 months in which simulation output 
data is generated. The 19 month period is divided into 1 month batches. The simulation output metrics are generated by using the batch means variance reduction technique (Law and Kelton, 2000). In the 19 month data period, a 1 month batch of data gathering is followed by a dead period in which the simulation output is not used in the simulation output statistics. In total 10 batches are generated for the simulation output, and the average values of these simulation output metrics are used as simulation output results. The results presented are the average batch means results of the simulation.

\section{Results}

The results of the VHC study are presented in three sections below. The terms STOCK\%, PIPE\%, BTO\% and VHC\% are used for the proportion of orders fulfilled from stock, from the pipeline, by Build-to-Order, and from the VHC (where relevant), respectively.

\subsection{The Effect of a VHC on System Performance}

Figure 4. shows the proportions of customers fulfilled by each of the fulfilment mechanisms for the four different systems. The results are summarised numerically in the first four rows of Table 2 (the percentages are rounded). The proportion of customers fulfilled through Build-toOrder (BTO\%) reduces substantially for the three non-VHC cases in moving from case 1 to

case 2, to case 3 . The introduction of a VHC reduces the BTO $\%$ further. Using stock trading in case 2 reduces BTO $\%$ by $15 \%$ from case 1 . Allowing stock compromise in case 2 results in a further reduction of $\mathrm{BTO} \%$ of $3 \%$. Introducing a $\mathrm{VHC}$ into the system results in a further reduction of $8 \%$ compared to the non-VHC case 3 system. The introduction of more fulfilment mechanisms reduces the need for BTO. 


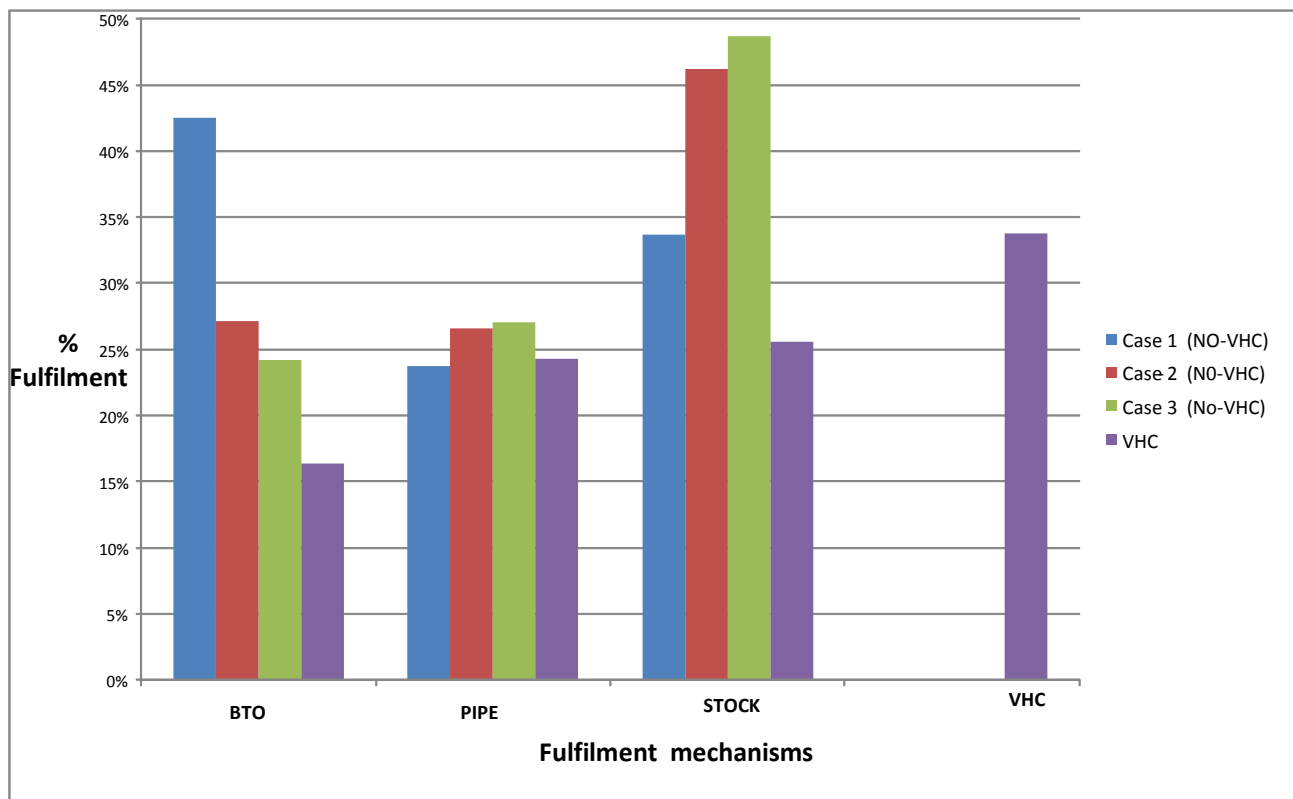

Figure 4. Fulfilment metrics for non-VHC systems and a VHC system

Table 2. Fulfilment performance for non-VHC systems and a VHC system

\begin{tabular}{|c|c|c|c|c|}
\hline & \multicolumn{3}{|c|}{ NO-VHC } & \multirow{2}{*}{ VHC CASE } \\
\hline & Case 1 (NCNT) & Case2 (NC) & Case 3 & \\
\hline BTO fulfilment & $43 \%$ & $27 \%$ & $24 \%$ & $16 \%$ \\
\hline Pipeline fulfilment & $24 \%$ & $27 \%$ & $27 \%$ & $24 \%$ \\
\hline Stock fulfilment & $33 \%$ & $46 \%$ & $49 \%$ & $59 \% *$ \\
\hline VHC fulfilment & N/A & N/A & N/A & $34 \%$ \\
\hline $\begin{array}{l}\text { Average customer } \\
\text { lead time (days) }\end{array}$ & 27.8 & 17.3 & 15.3 & 8.3 \\
\hline $\begin{array}{l}\text { Average system stock } \\
\text { level (vehicles) }\end{array}$ & 8377 & 6413 & 6048 & 7374 \\
\hline
\end{tabular}

* In the VHC system stock fulfilment includes fulfilment from both local dealer stock and VHC stock.

For each of the systems, the proportions fulfilled by each of the fulfilment mechanisms are inter-related. Thus, the relatively low stock fulfilment for non-VHC case 1 is matched by its relatively high BTO\%. The introduction of a VHC has a significant impact on the proportion of customers fulfilled from stock. The VHC system has a total of 59\% fulfilment from stock (i.e. $\mathrm{STOCK} \%+\mathrm{VHC} \%$ ) compared to $47 \%$ for the non-VHC case 3 system. The pipeline 
fulfilment metrics are only marginally affected by the introduction of a VHC. The PIPE\% in the VHC system is $3 \%$ less than that of the non-VHC case 3 system, which is complemented by the VHC systems larger fulfilment from total stock.

Figure 5 shows the mean lead times (right-hand vertical axis) and the mean stock levels (lefthand vertical axis) for each of the four systems. The results are summarised numerically in last two rows of Table 2. Introducing a VHC has a large beneficial effect on mean lead times in the system. When a VHC is used the lead time is approximately halved compared to the non-VHC case 2 and non-VHC case 3 systems (a 52\% and a 46\% reduction, respectively). The mean lead time for the VHC is approximately a third of that of the non-VHC case 1 system.

Figure 5 also shows the mean system stock levels, which is the sum of local stocks of dealers for the non-VHC systems and is the sum of VHC stock and local dealer stock in the case of the VHC system. The VHC system shows a reduction in system stock of $12 \%$ compared to the non-VHC case 1 system. However, it shows an increase in mean stock compared to the nonVHC case 2 and case 3 systems of $15 \%$ and 22\%, respectively. The main reason behind the increase in the stock level are customers that seek demonstrator vehicles from a dealer and that are fulfilled only from the local stock in the system. The impact of this type of customer for VHC systems with a high level of stock allocation is discussed further in section 5.2 below.

Thus, in summary, introducing a VHC in an open pipeline system with typical VHC operating conditions reduces the lead time in the system significantly but results in increased stock levels compared to systems operating with some stock trading (non-VHC cases 2 and 3). If there is no stock trading in the system, as in non-VHC case 1 system, establishing a VHC is 
the only enabler of stock trading across dealers and the VHC reduces both the mean lead time and mean stock level metrics.

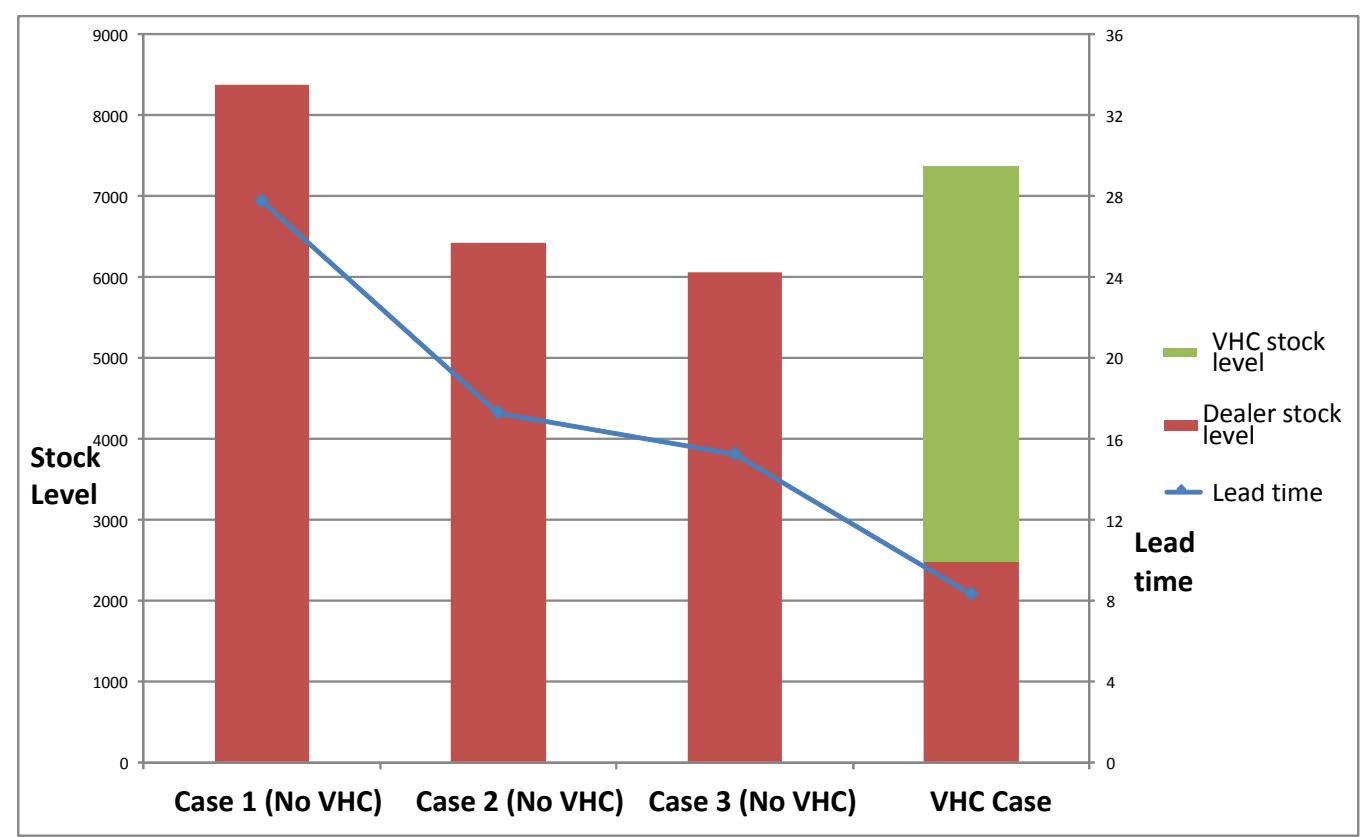

Figure 5. Mean stock level and mean lead time performance for three non-VHC systems and a VHC system.

\subsection{The Effect of VHC-Local Stock Split}

Here we consider the effect on fulfilment of changes in the proportion of unsold vehicles sent to the VHC from the pipeline. No other changes are made to the operating policies from those used in the VHC system in 5.1 above. Figure 6 shows the effects on each of the fulfilment mechanisms as the VHC stock split changes from $0 \%$ to $100 \%$ in increments of $10 \%$. In all experiments, vehicles in the VHC that remain unsold are auto-shipped to the relevant local dealers after 90 days.

As the stock split ratio increases from $0 \%$ to $100 \%$, VHC fulfilment increases from $5 \%$ to 42\%. There is a corresponding decrease in local stock fulfilment from $49 \%$ to $27 \%$. Fulfilment through BTO decreases from $24 \%$ to $14 \%$ as the proportion of stock sent to the VHC increases from $0 \%$ to $100 \%$. Pipeline fulfilment is relatively insensitive to changes in 
the split ratios below $60 \%$, remaining at approximately $26 \%$ up to that point. As the $\mathrm{VHC}$ allocation increases from $60 \%$ to $100 \%$, pipeline fulfilment reduces to $17 \%$.

Figure 6 shows how fulfilment from local stock and fulfilment from the VHC change as the VHC allocation changes. Total stock fulfilment (local stock fulfilment + VHC fulfilment) increases from $49 \%$ to $69 \%$ as the VHC stock ratio increases from $0 \%$ to $100 \%$. A decrease in local stock fulfilment is observed up to $70 \%$ VHC stock but local stock fulfilment is fairly constant after that point. This behaviour is directly related to the characteristics of a particular demand type identified in the analysis of the producer's data set, which we call here the demonstrator type. This type of demand is significant in the market studied and can only be fulfilled from local stock. It is assumed customers for demonstrator vehicles are willing to fully compromise on all features of such a vehicle, i.e. they can be fulfilled with any vehicle provided it is local stock.

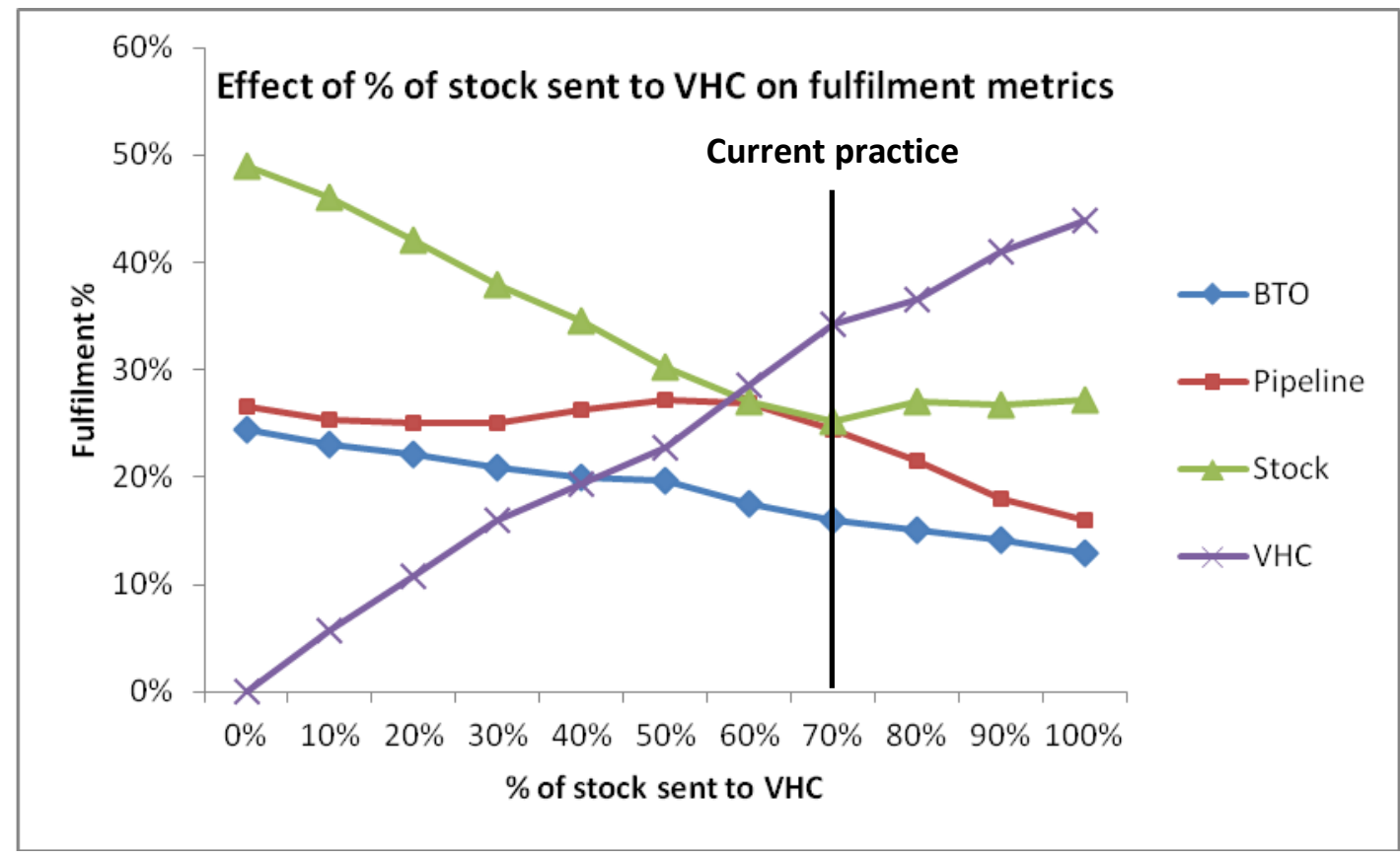

Figure 6. Effect of VHC/Local stock split on each fulfilment mechanism 
Figure 7 shows the effects of the VHC-Local stock split on stock levels (left-hand vertical axis) and lead time (right-hand vertical axis). As the VHC stock percentage increases from $0 \%$ to $100 \%$, the local stock level in the system decreases from 6,048 to 2,924 units, and the stock in VHC increases from 0 to 11,039 units. Hence, the total stock in the system more than doubles when the extremes are considered (from 6,048 to 13,964 units). When the total stock level is further analysed, it reduces from 6,048 to 5,432 units when the VHC stock percentage increases from $0 \%$ to $40 \%$, with the minimum total stock level being observed when approximately $40 \%$ of vehicles are sent to VHC. Total stock in the system tends to increase monotonically as the VHC stock percentage increases above $40 \%$. The system stock level for a $60 \%$ VHC stock percentage is 6,079 units, very close to the level observed in a system without a VHC.

The lead time in the system tends to decrease monotonically as the VHC stock percentage increases. The lead time is 15.3 days with $0 \%$ VHC stock, and 5.6 days for $100 \%$ VHC stock. For a $40 \%$ VHC stock percentage, where the total stock in the system is at a minimum, the lead time is 10.8 days, and for $60 \%$ VHC stock the lead time is 9.7 days.

Thus, increasing the VHC stock percentage decreases the lead time significantly, but for high VHC stock allocations the system suffers with high levels of system stock. When the VHC stock percentage increases from $0 \%$ to $40 \%$ both lead time and stock level metrics improve; lead time reduces by $29 \%$ and system stock reduces by $10 \%$. As the VHC stock percentage increases from $40 \%$ to $60 \%$ the lead time decreases to 9.7 days (a $36 \%$ reduction from $0 \%$ VHC stock), and total stock in the system increases to 6,079 units (a less than $1 \%$ increase from $0 \%$ VHC stock percentage). At $60 \%$ VHC stock the system does not benefit from a stock reduction, but does benefit from a reduction in lead time. 
A reason identified behind the increase in stock level for VHC split ratios above $60 \%$ relates to the demonstrator demand type, which accounts for $21 \%$ of dealer demand in the demand data provided by the producer. Customers for demonstrator vehicles are fulfilled only from local stock and cannot be fulfilled from the VHC. Hence for high VHC stock allocations these customers must wait for VHC vehicles to be auto-shipped to local dealer stock to be fulfilled. As the system has a significant proportion of demand coming from customers that can only be fulfilled from local dealer stock, decreasing local stock levels thus leads to increases in VHC stock and increased waiting for this class of customer. A corollary is that the proportion of unsold products sent to the VHC should be determined taking into account the market shares of different demand types in the system.

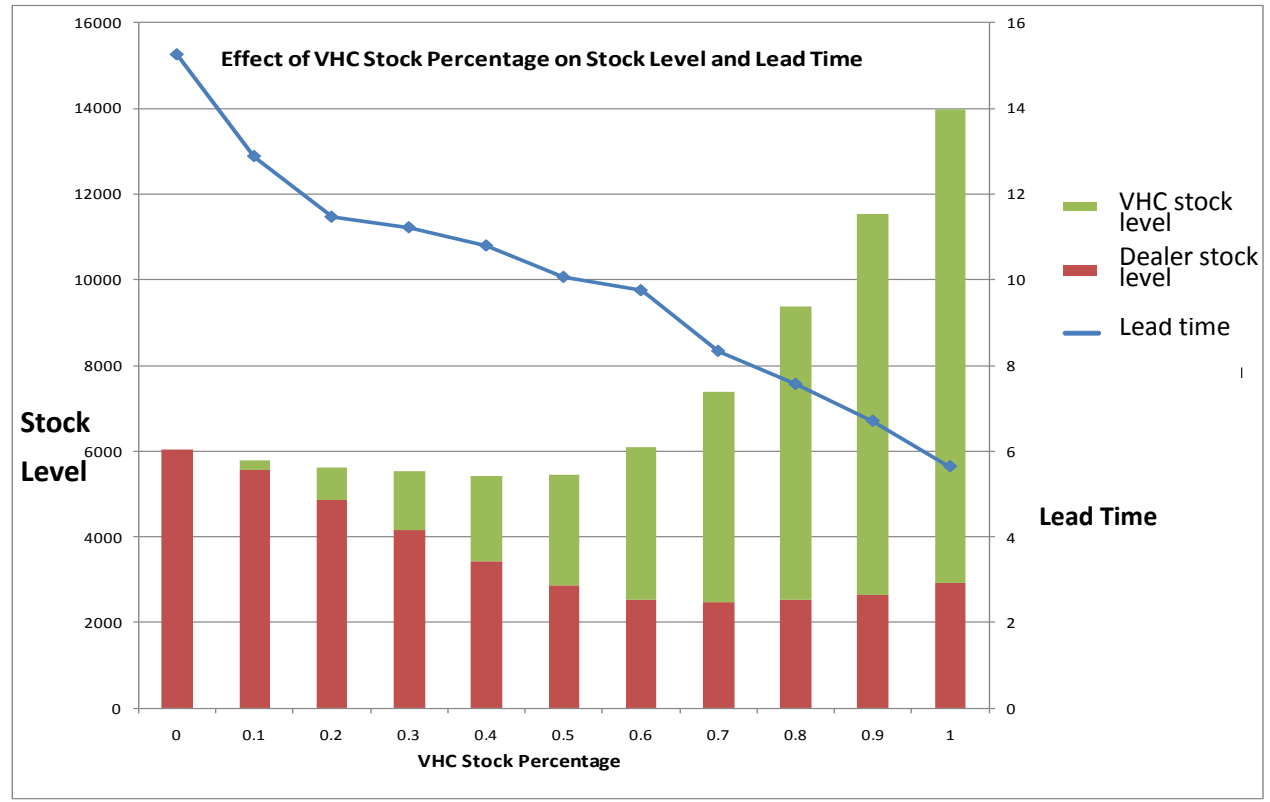

Figure 7. Effect of VHC - Local stock split on mean stock level and mean lead time

\subsection{The Effect of Auto-shipment Duration}

The auto-shipment duration is the maximum number of days an unsold vehicle can remain in the VHC. If the vehicle is not sold from the VHC within the auto-shipment duration, it is sent to the dealer to whom it was originally allocated. The general practice for the producer in 
markets in which it operates a VHC is to keep vehicles in the VHC for a maximum of 90 days before sending to the appropriate dealer. The study aimed to understand the effect of autoshipment duration on fulfilment mechanisms and on stock level and lead time. The experimental study varied the auto-shipment duration from 15 days to 210 days with 15 day increments. All other operating policies are the same as in the VHC system in section 5.1.

Figure 8 shows the effect of auto-shipment duration on each of the fulfilment mechanisms. Both BTO\% and PIPE\% are relatively insensitive to changes in the auto-shipment duration. The $\mathrm{BTO} \%$ is around $17 \%$ for the whole experimental range from 15 days to 90 days. A corollary to the insensitive behaviour of $\mathrm{BTO} \%$ and PIPE\%, is that total fulfilment from the total stock (STOCK\% + VHC\%) is not responsive to changes in auto-shipment duration. However, a switch from STOCK\% to VHC\% is observed for auto-shipment durations less than 75 days. For a 15 day auto-shipment duration, where the total stock fulfilment is 56\%, the $\mathrm{STOCK} \%$ is $37 \%$, and $\mathrm{VHC} \%$ is $19 \%$. When auto-shipment duration increases to 75 days the total stock fulfilment is $57 \%$, STOCK\% is $25 \%$ and $\mathrm{VHC} \%$ is $32 \%$.

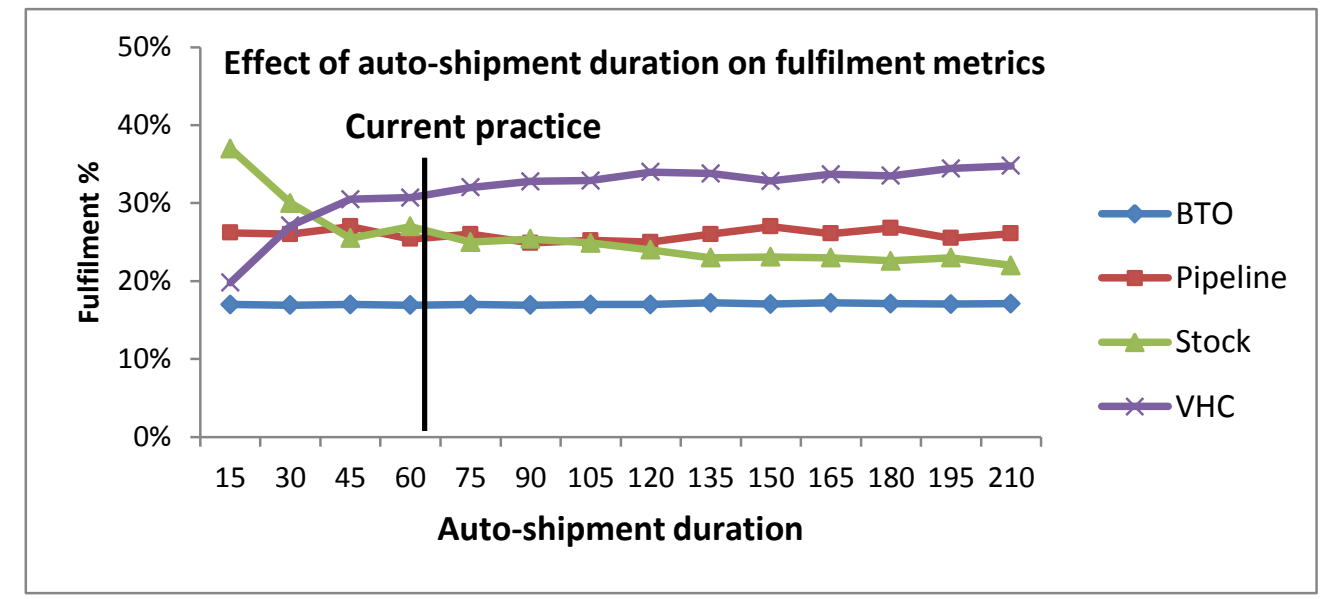

Figure 8. Effect of auto-shipment duration on each fulfilment mechanism

Figure 9 shows the effects of auto-shipment duration on mean lead time and mean stock levels. The customer lead time metric is insensitive to changes in auto-shipment duration. The 
mean lead time over the full range of auto-shipment durations is 9.3 days with minimum of 8.4 days (at 60 days auto-shipment duration) and a maximum of 9.9 days (at 150 days autoshipment duration). It should be noted that the apparent erratic variations evident in the lead time plot (see right-hand vertical axis) result from variation in the estimation of the mean from the simulation experiments.

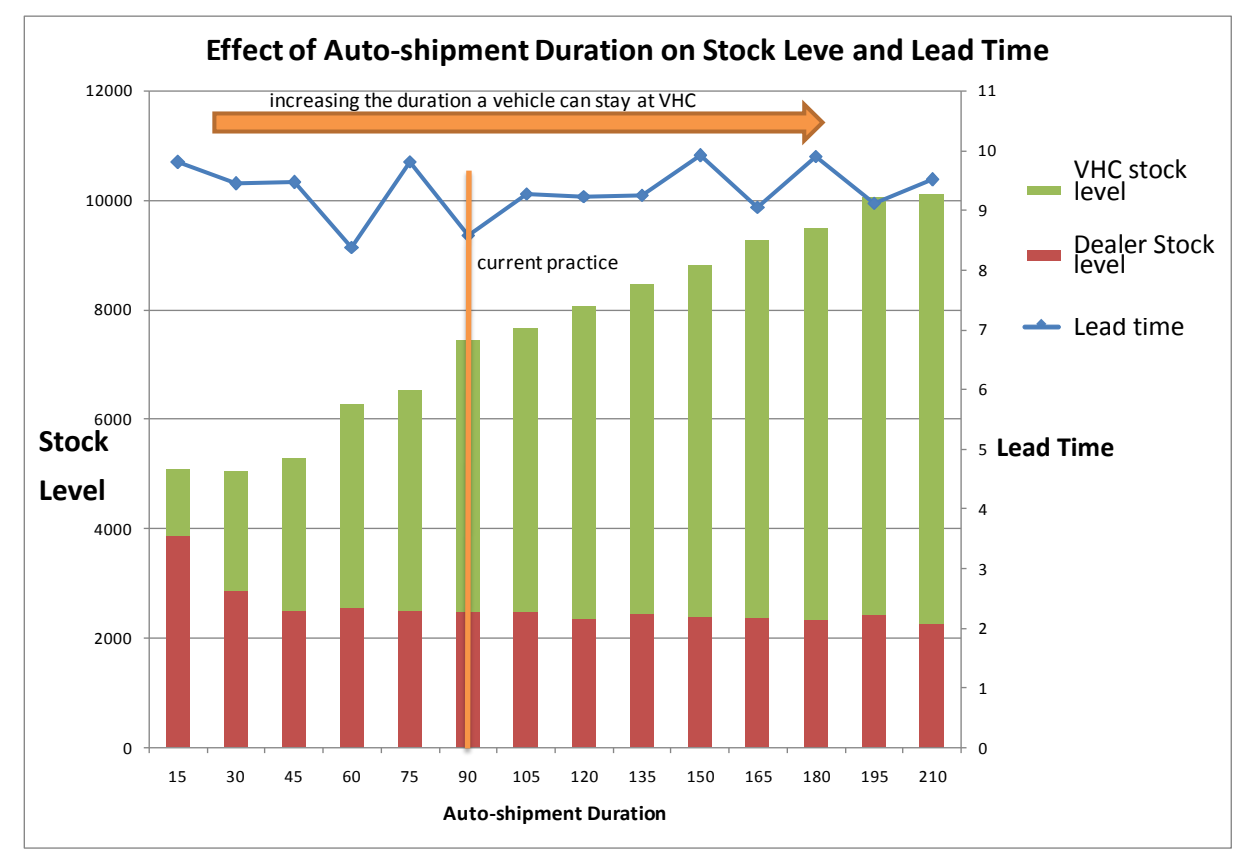

Figure 9. Effect of auto-shipment duration on mean stock level and mean lead time

The local stock in the system decreases as auto-shipment duration increases, from 3,863 units to 2,501 units for auto-shipment durations of 15 and 45 days, respectively. The corresponding VHC stock levels are 1,234 and 2,773 units. Hence, the total stock levels are 5,097 and 5,273 units for auto-shipment durations of 15 and 45 days. For auto-shipment durations higher than 45 days the total stock level increases monotonically from 5,273 to 10,093 units (for an autoshipment duration of 210 days). In summary, the experiments show that the fulfilment mechanisms and lead times are relatively insensitive to changes in auto-shipment duration but total stock levels increase with longer auto-shipment durations. 


\section{Discussion}

The study has investigated the effects on order fulfilment mechanisms and order fulfilment performance of establishing a central vehicle holding compound (VHC) in a real automotive market operating with an open pipeline. A VHC provides an additional mechanism for order fulfilment. Changing the fulfilment mechanisms is likely to affect system performance but, as noted in section 2, how it will affect performance is not predictable for a large scale system such as the one investigated without using simulation. The study shows that introducing a VHC changes the order fulfilment process and its performance significantly with some effects that may be viewed as beneficial by the producer and some that may be viewed negatively. In depth understanding and quantification of the effects of introducing a VHC in an open pipeline using a realistic simulation model provides valuable insights for the producer in systems design and management.

The producer is interested in how the fulfilment mechanisms may change with a VHC because the level of use of each mechanism has implications for the overall operation of the order fulfilment system and may require the producer to develop or enhance its own capabilities and the support it provides to dealers. The study shows that establishing a VHC reduces the required level of BTO. Knowledge about the expected level of BTO in the system is particularly important for the producer. Reducing the BTO\% may be viewed favourably because (1) it has a beneficial effect on lead time with customers being fulfilled from within the system rather than having to wait for a BTO vehicle, and (2) it reduces the need to accommodate BTO requests in planning and managing the pipeline. However, even for a system with a VHC, the BTO level does not fall below $15 \%$. Thus, the producer still needs to be able to facilitate at least the expected minimum level of BTO observed. 
Establishing a VHC has relatively little effect on the level of pipeline fulfilment, which remains at around a quarter of the total fulfilment in each of the systems studied. Pipeline fulfilment is facilitated by the information systems and tools provided by the producer for dealers to search the pipeline and these must still be supported by the producer. Establishing a VHC results in a change from fulfilment from local stock to fulfilment from the VHC. The level of change depends on the VHC operating policies, in particular the proportion of production sent to the VHC. Increasing the proportion of vehicles sent to the VHC increases fulfilment from total stock in the system, which may require the producer to develop and adapt its logistics systems to accommodate these changes.

The producer is also interested in the service level performance of the order fulfilment system, an important measure of which is the mean lead time experienced by customers. The study shows that establishing a VHC decreases the lead time significantly, regardless of the current operational policies in the market. The improvements in lead time result from the changes in the proportions of customers fulfilled by each fulfilment mechanism as lead times are determined by the position from which customers are fulfilled in system. Stock fulfilment dominates in the VHC system with the remainder of customers being fulfilled from the pipeline and a relatively small proportion fulfilled through BTO. Stock fulfilment results in the shortest fulfilment lead time whilst BTO fulfilment results in the longest lead time with pipeline fulfilment somewhere in between, depending on the position in the pipeline from which the customer is fulfilled.

If the producer is principally interested in fast response to customers then establishing a VHC for the market should be considered. However, the level of stock in the system is also a critical metric as it is an indicator of the costs of the producer and high stock levels may risk obsolescence. Establishing a VHC can increase the total system stock in comparison to a non- 
VHC open pipeline system operating with stock trading (cases 2 and 3). From the producer's perspective the benefits of increased customer satisfaction gained through lead time reduction from introducing a VHC must be balanced against the increased costs that may be incurred in holding higher levels of stock in the system for some VHC operating conditions. However, this is affected by how the VHC operates. For the VHC system studied, the minimum stock level is observed when approximately $40 \%$ of vehicles are sent to the VHC. With a $60 \%$ VHC stock split, the total system stock is at a similar level to a non-VHC system and the mean lead time is almost 5 days lower than the non-VHC system. Thus, the producer can gain benefits of much reduced lead time without incurring large increases in stock by operating a VHC with appropriate policies.

The maximum duration for vehicles in the VHC is important for the producer and dealers as it is related to contractual issues and the ownership of the vehicles. In general ownership is transferred to the dealer once a vehicle is shipped. The study shows that increasing the autoshipment duration increases the total stock level in the system. However, lead time is relatively insensitive to changes in auto-shipment duration. Changes in the auto-shipment duration have only relatively small effects on the proportions of customers fulfilled through each of the fulfilment mechanisms for durations beyond 45 days. Thus, the maximum autoshipment duration could be reduced significantly without affecting fulfilment performance. For the system studied, the auto-shipment duration could be halved, with BTO\%, PIPE\%, total stock fulfilment and lead time metrics remaining relatively unchanged, but reducing system stock by $29 \%$, compared to the system operating with a 90 day period. Reducing the maximum duration of stay for vehicles in a VHC may involve a change of ownership of vehicles from the producer to dealers. Clearly demonstrating that the normal contractual autoshipment duration could be substantially reduced is very important for the producer to know, although implementing changes may involve contractual issues beyond the scope of this study. 
Introducing a VHC in a specific market will incur investment costs and may change operational costs on the part of the producer and these are areas worthy of further study. We note, however, that how the logistics and stock holding cost structures may change with different fulfilment mechanisms is complex, in particular with regard to which party bears which costs. These could vary substantially depending on the producer's policies, and contracts and negotiations with dealers, which may be influenced by dealer size/volume and the bargaining power of different parties. For instance, the producer might decide to bear all the costs of logistics from the VHC to dealers or only the logistics costs for vehicles which the dealer had originally ordered. The study here helps inform a cost-benefit study as it provides clear evidence on how the fulfilment mechanisms will change with the addition of a VHC under different operating conditions.

The results and the insights shown in the study and discussed above on the three principal metrics - the proportions fulfilled by each mechanism, mean lead time experienced by customers and mean stock level in each of the systems - are valuable in providing information to support cost-benefit decision making. A further factor to be considered in changing the order fulfilment system is the increased revenue generation opportunities that may result from improved service levels to customers. Importantly, in considering such a decision, the study shows that increasing the use of trading by dealers may alone offer significant benefits. This can be facilitated by providing enhanced information systems tools and mechanisms to trade and encouraging dealers to use them. If a VHC is established, its operating parameters need to be aligned with the nature of demand observed in the market to gain maximum benefits from the additional fulfilment flexibility. Misalignment of VHC operating policies with the demand types and fulfilment mechanisms can cause deterioration in system performance. The relative changes observed are different when the VHC system is compared with each of the three non- 
VHC systems. Thus, the relative impacts of establishing a VHC in an open pipeline need to be evaluated in relation to the operating policies currently in use in the existing the system and the conditions in the market. Finally, the maximum duration for vehicles in the VHC should be considered with care. As with the system here, a significant reduction in the maximum duration may be possible without reducing service levels or significantly increasing stock levels.

\section{Conclusions}

Satisfying customer requests for specific vehicle specifications in a timely manner is increasingly important in the automotive sector (WSJ, 2014). It will improve customer satisfaction and may increase profit margins for both the producer and dealers. Thus, producers need to consider all avenues for increasing flexibility in order fulfilment, including the establishment of a VHC. This study has examined the effects on order fulfilment performance of introducing a VHC in an automotive market that operates with open pipeline principles. The study has provided detailed insights into the potential effects and benefits that may result and the operational factors that need to be considered in using a VHC.

This is one of the few reported studies that have sought to capture and model a large scale contemporary automotive order fulfilment system including the full range of dealers operating in a full market. The simulation model developed with the producer encompasses both the customer demand process through dealers as well as the key decision making processes that link the producer and dealers. It captures a realistically high level of product variety. Although the model is large and sophisticated, like all modelling studies it has limitations. The study has focused on and used data from a large and important market for the producer. Markets with different demand characteristics and different types and numbers of dealers may yield different results. However the simulation environment allows markets with different 
demand characteristics and different numbers of dealers to be investigated. We note that the study was not designed to examine seasonal demand fluctuations or customers that are not satisfied and do not make a purchase. Each of these factors could be examined but would need further data and information to undertake such studies. We also note that the study has not considered the operating costs for each fulfilment mechanism in this study. It has concentrated on three key performance metrics used by the producer - the proportions of customers fulfilled by each fulfilment mechanism, mean lead time and mean stock level. The observed changes in these metrics can inform a cost-benefit study. Further studies examining operational costs in more detail could be undertaken. Effective and efficient order fulfilment processes for complex products with many variants are challenging to design and manage. The insights from the study here have relevance to other sectors that share some of the characteristics of the automotive sector, in particular those with high variety and long planning pipelines.

\section{Appendix}

\section{Definition of terms (alphabetically)}

Auto-shipment: the process of automatically sending a vehicle that has remained unsold in the VHC after a maximum duration to the dealer to which it was originally allocated. Auto-shipment duration: the stipulated maximum number of days an unsold vehicle can remain in the VHC.

BTO (Build-to-Order) refers to a vehicle that is ordered by a dealer to meet a specific customer's specification. A BTO is generated if the dealer fails to find a vehicle in stock or in the planning pipeline that can meet the customer's request.

BTO\% (Build-to-Order percentage): the proportion of customers fulfilled through the BTO fulfilment mechanism 
Customer order: a vehicle specification requested by a customer from a dealer.

Dealer trading: refers to a dealer's ability to search other dealers stock or vehicles in the pipeline to fulfil a customer order.

Fulfilment mechanism: the way a customer order is fulfilled by a dealer - through a BTO, from the pipeline, or from stock. If the system has a VHC, the fulfilment mechanisms also include VHC stock fulfilment and fulfilment from local dealer stock.

Lead time: the number of days a customer has to wait from placing an order with a dealer to receiving a vehicle.

Local stock: stock held by dealers in their premises that has yet to be sold to a customer.

Open pipeline: an order fulfilment system where a customer may fulfilled by different fulfilment mechanisms including by BTO, from the pipeline, from stock (which may include VHC fulfilment if there is a VHC in the system).

Pipe: refers to fulfilment from the pipeline

PIPE\%: the proportion of customers fulfilled through the pipeline fulfilment mechanism.

Pipeline: refers to vehicles that are in planning and in assembly.

Stock: refers to already assembled vehicles across the system.

STOCK\%: the proportion of customers that are fulfilled from stock. For a system without a VHC this refers to fulfilment from the local stock of dealers. For a system with a VHC this includes fulfilment from VHC stock and fulfilment from dealers' local stock.

Total Stock: refers to the total level of stock of assembled vehicles anywhere in the system. VHC (Vehicle Holding Compound): A central compound that stores a proportion of the unsold vehicles for a specified maximum duration.

VHC\%: the proportion of customers that are fulfilled from stock in the VHC. 


\section{References}

Agrawal, M., T. V. Kumaresh, G. Mercer. 2001. The false promise of mass customization. McKinsey Quarterly, 3: 62-71.

Alford, D., P. Sackett, G. Nelder. 2000. Mass customisation—an automotive perspective. International Journal of Production Economics, 65(1): 99-110.

Almeder, C., Preusser, M., and Hartl, R. F. (2009). Simulation and optimization of supply chains: alternative or complementary approaches? OR Spectrum, 31(1):95-119.

Banks, J., 2001. Discrete-event system simulation. Prentice-Hall international series in industrial and systems engineering.3rd ed. Upper Saddle River, NJ, Prentice Hall.

Brabazon, P. G., MacCarthy B. L. 2006. Fundamental Behaviour of Virtual-Build-to-Order Systems. International Journal of Production Economics. 104 (2): 514-524.

Brabazon, P. G., \& MacCarthy, B. L. 2010. On Markovian approximations for virtual-buildto-order systems. Journal of the Operational Research Society. 61(10): 1471-1484.

Brabazon, P. G., MacCarthy, B. L. 2012. Investigating a long tail in retail vehicle sales. Omega. 40(3): 302-313.

Brabazon, P. G., MacCarthy, B., Woodcock, A., Hawkins, R. W. 2010. Mass Customization in the automotive industry: comparing interdealer trading and reconfiguration flexibilities in order fulfillment. Production and Operations Management. 19(5): 489-502.

Chen, I. J., Calantone, R. J., \& Chung, C. H. (1992). The marketing-manufacturing interface and manufacturing flexibility. Omega, 20(4), 431-443.

De Toni, A., \& Tonchia, S. (1998). Manufacturing flexibility: a literature review. International Journal of Production Research, 36(6), 1587-1617.

Denton, B., D. Gupta, K. Jawahir. 2003. Managing increasing product variety at integrated steel mills. Interfaces. 33(2): 41-53.

Fredriksson, P., L.-E. Gadde. 2005. Flexibility and Rigidity in Customization and Build-toorder Production. Industrial Marketing Management. 34 (7): 695-705. 
Herer, Y.T., Tzur, M., Yucesanc, E. 2002. Transshipments: An emerging inventory recourse to achieve supply chain leagility. International Journal of Production Economics, 80(3): 201- 212.

Holweg, M., F. K. Pil., 2004. The Second Century: Reconnecting Customer and Value Chain through Build-to-Order. MIT Press, Cambridge, MA.

Holweg, M., Disney, S., Hines, P. \& Naim, M. 2005. Towards responsive vehicle supply: a simulation-based investigation into automotive scheduling systems. Journal of Operations Management, 23(5), 507-530.

Koste, L. L., \& Malhotra, M. K. 1999. A theoretical framework for analyzing the dimensions of manufacturing flexibility. Journal of Operations Management, 18(1), 75-93.

Law, A. M. \& Kelton,W. D., 2000. Simulation Modeling and Analysis. 3rd edition. Boston and London: McGraw-Hill.

Lim, L. L., Alpan, G., \& Penz, B. 2014. Reconciling sales and operations management with distant suppliers in the automotive industry: a simulation approach. International Journal of Production Economics, 151, 20-36.

MacCarthy, B. L. 2013. An analysis of order fulfilment approaches for delivering variety and customisation. International Journal of Production Research, 51(23-24), 7329-7344.

MacCarthy, B. L., Ovutmen, T., Tarim, S. A., \& Brabazon, P. G. 2013. Exact and approximate solutions for fulfilment metrics in open pipeline order fulfilment systems. IMA Journal of Management Mathematics. 24(4): 381-405.

Meredith, J., U. Akinc. 2007. Characterizing and structuring a new make-to-forecast production strategy. Journal of Operations Management. 25(3): 623-642.

Ovutmen T, 2012. Open Pipeline Order Fulfilment Systems in the Automotive Sector: Analysis, Modelling and Simulation. PhD Thesis. University of Nottingham, Business School, UK. 
Özdemir, D., Yücesan, E., \& Herer, Y. T. 2006. Multi-location transshipment problem with capacitated transportation. European Journal of Operational Research. 175(1): 602-621.

Özdemir, D., Yücesan, E., \& Herer, Y. T. 2013. Multi-location transshipment problem with capacitated production. European Journal of Operational Research. 226(3): 425-435.

Paterson, C., Kiesmüller, G., Teunter, R., \& Glazebrook, K. 2011. Inventory models with lateral transshipments: A review. European Journal of Operational Research. 210(2): 125136.

Pibernik R (2005), Advanced available-to-promise: Classification, selected methods and requirements for operations and inventory management, International Journal of Production Economics, 93-94, pp 239-252

Sargent, R. G. (2013). Verification and validation of simulation models. Journal of Simulation, $7(1), 12-24$.

Seebacher, G., \& Winkler, H. (2013). A citation analysis of the research on manufacturing and supply chain flexibility. International Journal of Production Research, 51(11), 34153427.

Stäblein, T., Baumgärtel, H., \& Wilke, J. (2007). The Supply net simulator SNS: An artificial intelligence approach for highly efficient supply network simulation. In Management logistischer Netzwerke (pp. 85-110). Physica-Verlag HD.

Stablein, T., Holweg, M., Miemczyk, J., 2011. Theoretical versus actual product variety: how much customisation do customers really demand? International Journal of Operations and Production Management. 31(3): 350-370.

Stablein, T., \& Aoki, K. 2015. Planning and scheduling in the automotive industry: A comparison of industrial practice at German and Japanese makers. International Journal of Production Economics, 162 (2): 258-272.

Stadtler, H., \& Kilger, C. 2010. Supply Chain Management and Advanced Planning: Concepts, Models, Software, and Case Studies, 4th edition, Springer. 
Swaminathan, J. M., \& Tayur, S. R. 1998. Managing broader product lines through delayed differentiation using vanilla boxes. Management Science, 44(12-part-2), S161-S172.

Tomino, T., Park, Y., Hong, P., \& Roh, J. J. 2009. Market flexible customizing system (MFCS) of Japanese vehicle manufacturers: An analysis of Toyota, Nissan and Mitsubishi. International Journal of Production Economics, 118(2), 375-386.

WSJ (2014). 'Luxury Auto Makers Fill Lineups With Dizzying Array of Models', http://online.wsj.com/news/articles/ (Boudette N. E. \& White J. B. 17/1/2014). 